\title{
COVID-19-related knowledge, attitudes, and practices among adolescents and young people in Bihar and Uttar Pradesh, India: Study description
}

\author{
Rajib Acharya \\ Population Council \\ Mukta Gundi \\ Population Council \\ Thoai Ngo \\ Population Council \\ Neelanjana Pandey \\ Population Council \\ Sangram Kishor Patel \\ Population Council \\ Sertow xtpageforadditional authors \\ Part of the Demography, Population, and Ecology Commons, and the International Public Health \\ Commons \\ How does access to this work benefit you? Let us know!

\section{Recommended Citation} \\ Rajib Acharya, Mukta Gundi, Thoai Ngo, Neelanjana Pandey, Sangram Kishor Patel, Jessie Pinchoff, Shilpi \\ Rampal, Niranjan Saggurti, K.G. Santhya, Corinne White, and A.J. Francis Zavier. 2020. "COVID-19-related \\ knowledge, attitudes, and practices among adolescents and young people in Bihar and Uttar Pradesh, \\ India: Study description." New Delhi: Population Council.
}




\section{Authors}

Rajib Acharya, Mukta Gundi, Thoai Ngo, Neelanjana Pandey, Sangram Kishor Patel, Jessie Pinchoff, Shilpi Rampal, Niranjan Saggurti, K.G. Santhya, Corinne White, and A.J. Francis Zavier 
COVID-19-related knowledge, attitudes, and practices among adolescents and young people in Bihar and Uttar Pradesh, India ${ }^{1}$

Study Description

April 23, 2020

Authors: Rajib Acharya ${ }^{1}$, Mukta Gundi ${ }^{1}$, Thoai D. $\mathrm{Ngo}^{2}$, Neelanjana Pandey ${ }^{1}$, Sangram K. Patel ${ }^{1}$, Jessie Pinchoff $^{2}$, Shilpi Rampal ${ }^{1}$, Niranjan Saggurti ${ }^{1,3}$, K.G. Santhya ${ }^{1,3}$, Corinne White ${ }^{2}$, A.J.F. Zavier ${ }^{1}$

\section{Affiliations:}

1. Population Council, New Delhi, India

2. Poverty, Gender, and Youth Program, Population Council, New York, NY

3. Population Council Institute, New Delhi, India

\section{Corresponding authors:}

K.G. Santhya, PhD

Senior Associate, India, Poverty, Gender, and Youth Program +911124642901

kgsanthya@popcouncil.org

Thoai D. Ngo, PhD, MHS

Director, Poverty, Gender, and Youth Program

(212) 339-0500

tngo@popcouncil.org

\section{POPULATION COUNCIL}

IDEAS. EVIDENCE. IMPACT.

One Dag Hammarskjold Plaza

New York, NY 10017

www.popcouncil.org

\footnotetext{
${ }^{1}$ This document is evolving due to the nature of the COVID-19 response and will be updated as needed.
} 


\section{Abstract:}

To control the spread of COVID-19 in India and to aid the efforts of the Ministry of Health and Family Welfare (MOHFW), the Population Council and other non-governmental organizations are conducting research to assess residents' ability to follow sanitation and social distancing precautions under a countrywide lockdown. The Population Council COVID-19 study team is implementing rapid phonebased surveys to collect information on knowledge, attitudes and practices, as well as needs, among 2,041 young people (ages 19-23 years) and/or an adult household member, sampled from an existing prospective cohort study with a total sample size of 20,574 in Bihar $(n=10,433)$ and Uttar Pradesh ( $n=10,141)$. Baseline was conducted from April 3-22; subsequent iterations of the survey are planned to be conducted on a monthly basis. Baseline findings on awareness of COVID-19 symptoms, perceived risk, awareness of and ability to carry out preventive behaviors, misconceptions, and fears will inform the development of government and other stakeholders' interventions and/or strategies. We are committed to openly sharing the latest versions of the study description, questionnaires, deidentified or aggregated datasets, and preliminary results. Data and findings can also be shared with partners working in COVID-19 response.

\section{Background}

Global health experts and South Asian governments have expressed concern about the spread of COVID19 and potential for more than 7.6 million deaths in South Asia if no action were taken (Walker et al, 2020). India reported its first COVID-19 case on January 30, 2020 and numbers began to rise in late March 2020, ("Johns Hopkins Coronavirus Resource Center," 2020) albeit at a low rate, which may be attributed to several government policies including stopping all international flights and implementing a nation-wide lockdown at an early stage of the pandemic. By early April 2020, country officials had identified several areas as hotspots of COVID-19 infections in the country. India faces threat of a serious outbreak due to deep challenges in practicing social distancing and access to water and soap for handwashing, with densely populated urban areas and a highly mobile population in some states. The country announced an initial 3-week lockdown period on March 24, now extended until May 3, triggering rapid migrations from the cities to rural areas in some parts of the country among rising fears of fast spread of infections. The extension of the initial lockdown period poses further challenges to the already distressed population and to ensuring strict compliance with social distancing guidelines.

In India, where approximately $80 \%$ of the workforce is employed in the informal sector and about a third are employed as day-laborers, the lockdown policy may exacerbate existing health and economic inequalities (The Lancet, 2020). Uttar Pradesh and Bihar are two of the poorest states in India, thus are at particularly high risk of adverse health and economic effects of a COVID-19 outbreak and ongoing lockdown, since most people from these two states work in the informal sector.

Implementing personal hygiene and public health behaviors such as handwashing and social distancing are necessary to curb the spread of coronavirus, but it will be challenging to practice these in many cities and rural areas in developing settings (Dahab et al, 2020). Without sustained bans on large gatherings (including specific cultural and faith practices such as mass prayer gatherings, large weddings and 
funerals) these may create super-spreading events that accelerate transmission (Wong et al, 2015). This situation may be compounded by the spread of COVID-19 misinformation including unsupported treatments or promotion of ineffective preventive behaviors (loannidis, 2020; Vigdor, 2020). To successfully "flatten the curve" in India, extensive and effective mitigation efforts will be required and for that health authorities will need timely and actionable data to design policies and interventions that are easily understood and relevant to beneficiaries' lives.

The Indian Ministry of Health and Family Welfare (MOHFW) along with state-level health departments have been providing information on COVID-19 through both subnational communication channels and through a mobile app, Aarogya-Setu. The Population Council India, together with other nongovernmental organizations, will be conducting a mobile phone-based knowledge, attitudes and practices (KAP) survey and needs assessment in Bihar and Uttar Pradesh. Results will be shared with MOHFW and inform the development and targeting of behavior change campaigns, COVID-19 tracking, and other interventions as needed throughout the pandemic.

\section{Research Questions}

Collecting KAP surveys among at-risk populations is useful to inform prevention, control and mitigation measures during epidemics. A recent example is from the Ebola response, where KAP surveys yielded critical information to guide response and recovery efforts, health education, and social mobilization. KAP surveys during Ebola identified the prevalence of misconceptions about Ebola transmission and prevention, the need to prevent stigmatization of Ebola survivors, and to foster safer case management and burial practices (Jalloh et al, 2017). Information from these surveys is pivotal for policymakers and program implementers to use only during the outbreak and the recovery stages. We are undertaking a series of KAP surveys among young people and/or adult members in their household in Bihar and Uttar Pradesh to answer the following questions:

1. What are the current knowledge, attitudes, and practices reported by households related to COVID-19? How do these change over time?

2. What are the main barriers to adoption of key behaviors for COVID-19 prevention (handwashing, social distancing)?

3. What are the household and community-level needs that must be met to enable behavior change and prevent COVID-19 transmission?

4. How has the COVID-19 pandemic affected the lives of migrants?

5. How has the COVID-19 containment strategy affected community's access to sexual and reproductive health services?

\section{Research Design}

This study will deploy rapid phone-based KAP surveys with the young people or heads of households sampled from an existing Population Council led, state-representative, prospective cohort study of adolescents, Understanding the Lives of Adolescents and Young Adults (UDAYA). UDAYA was launched in 2015 and includes adolescents residing in Bihar $(n=10,433)$ and Uttar Pradesh $(n=10,141)$. UDAYA 
households eligible for inclusion in the COVID-19 survey were those in which we interviewed a 15-19year-old boy or girl in 2015-16 and that shared their telephone number with the research team for any future follow-up surveys. The most recent round of UDAYA data collection was 2018. The study team contacted available phone numbers to establish a baseline of 2,041 respondents. Once a baseline cohort is determined, subsequent iterations of the survey will be conducted every month (funds permitting), beginning in April 2020. Each survey will last less than 30 minutes and be conducted on the phone by a team of research assistants. The research team will attempt to contact these participants at least three times. Baseline findings on awareness of COVID-19 symptoms, perceived risk, awareness of and ability to carry out preventive behaviors, misconceptions, and fears will inform government generated behavior change communication messages for dissemination.

\section{Target population}

Our target population is households enrolled in the UDAYA study cohort described above, comprised of adolescents and young people living in Bihar and Uttar Pradesh. Young people and/or their family member who are interviewed will serve as the COVID-19 cohort in future survey rounds and studies. We aim to describe the experiences of adolescents and young adults residing in households in Bihar and Uttar Pradesh, and how they are responding to the COVID-19 pandemic.

\section{Survey instrument}

The first survey will serve as a baseline. The survey instrument includes questions regarding awareness of COVID-19, perceived risk of infection, awareness of promoted behaviors, misconceptions regarding treatment and disease spread, and will ask questions about perceived ability to carry out preventive behaviors by the respondent and their community, migration of family members and their experiences of stress. We will include some questions for only females, including access to sexual and reproductive health services, and experiences of violence. Our much larger dataset from UDAYA surveys in 2015 and 2018 can complement these rapid phone-based surveys, adding additional context (such as household location, household socioeconomic status, household composition, cooking indoors, transportation options, and gender attitudes). Subsequent rounds of data collection will ask some of the same questions to see how knowledge, attitudes and practices change over time, and may include additional modules related to exposure to behavior change messaging and responses to these campaigns.

\section{Limitations}

During the COVID-19 outbreak, it will not be possible to collect data or conduct behavior change campaigns in person, to protect health workers and field-based staff. Behavior change messages will have to rely on channels that do not require face-to-face interaction, such as SMS/WhatsApp, phone calls, radio, television, and social media. Our data collection will be conducted on the phone if phone numbers are no longer functional. Also, our sample is representative of the UDAYA cohort, but not of the general population. Only households with an adolescent or young adult was eligible for inclusion in UDAYA, so for example, households with only elderly individuals or with only young children would not be included in UDAYA and thus not including in the list of phone numbers for the COVID-19 survey.

\section{Contribution to Response}




\section{Relationship with government and other stakeholders}

We aim to share research findings with national and state government entities to inform the development of their COVID-19 control measures and to understand the barriers to adherence to social distancing guidelines. We will continue to work with other civil society organizations to understand and address the needs of migrants and adolescents.

\section{Gender lens}

Women and girls are highly vulnerable during an epidemic or crisis, it is critical to disaggregate by gender in all of our analyses. In many settings, women and girls are at increased risk during an epidemic because they are responsible not only for caring for the elderly and children, but because they often make up more than half of the healthcare workforce (Wenham et al, 2020). Financial opportunities and access to resources, information, and support will be severely affected as schools and businesses close and social distancing measures are put in place. Sexual and gender-based violence is already very prevalent in these communities. In humanitarian emergencies and noted in China after COVID-19 lock down, risk of gender-based violence increases (Wanqing, 2020).

\section{Open access}

We are committed to openly sharing the latest version of this study description, questionnaires, datasets, and preliminary results. Please visit the Population Council COVID-19 Research \& Evaluations page on Dataverse regularly for updates.

\section{References}

Dahab, M., van Zandvoort, K., Flasche, S., Warsame, A., Spiegel, P. B., Waldman, J., \& Checchi, F. (2020, March 20). COVID-19 control in low-income settings and displaced populations: What can realistically be done? https://www.Ishtm.ac.uk/newsevents/news/2020/covid-19-control-low-income-settings-anddisplaced-populations-what-can

Ezeh, A., Oyebode, O., Satterthwaite, D., Chen, Y.-F., Ndugwa, R., Sartori, J., Mberu, B., Melendez-Torres, G. J., Haregu, T., Watson, S. I., Caiaffa, W., Capon, A., \& Lilford, R. J. (2017). The history, geography, and sociology of slums and the health problems of people who live in slums. Lancet (London, England), 389(10068), 547-558. https://doi.org/10.1016/S0140-6736(16)31650-6

loannidis, J. P. A. (2020). Coronavirus disease 2019: The harms of exaggerated information and nonevidence-based measures. European Journal of Clinical Investigation, e13223.

https://doi.org/10.1111/eci.13223

Jalloh, M. F. (2017). Knowledge, Attitudes, and Practices Related to Ebola Virus Disease at the End of a National Epidemic-Guinea, August 2015. MMWR. Morbidity and Mortality Weekly Report, 66. 
Johns Hopkins Coronavirus Resource Center. (2020). Johns Hopkins Coronavirus Resource Center. https://coronavirus.jhu.edu/

Johnstone-Robertson, S. P., Mark, D., Morrow, C., Middelkoop, K., Chiswell, M., Aquino, L. D. H., Bekker, L.-G., \& Wood, R. (2011). Social Mixing Patterns Within a South African Township Community: Implications for Respiratory Disease Transmission and Control. American Journal of Epidemiology, 174(11), 1246-1255. https://doi.org/10.1093/aje/kwr251

The Lancet. (2020). Redefining vulnerability in the era of COVID-19. [editorial] The Lancet 395(10230): P1089. https://doi.org/10.1016/S0140-6736(20)30757-1

le Polain de Waroux, O., Cohuet, S., Ndazima, D., Kucharski, A. J., Juan-Giner, A., Flasche, S., Tumwesigye, E., Arinaitwe, R., Mwanga-Amumpaire, J., Boum, Y., Nackers, F., Checchi, F., Grais, R. F., \& Edmunds, W. J. (2018). Characteristics of human encounters and social mixing patterns relevant to infectious diseases spread by close contact: A survey in Southwest Uganda. BMC Infectious Diseases, 18. https://doi.org/10.1186/s12879-018-3073-1

Vigdor, N. (2020, March 24). Man Fatally Poisons Himself While Self-Medicating for Coronavirus, Doctor Says. The New York Times. https://www.nytimes.com/2020/03/24/us/chloroquine-poisoningcoronavirus.html

Walker, P., Whittaker C., Watser, O., et al (2020). The Global Impact of COVID-19 and Strategies for Mitigation and Suppression. WHO Collaborating Centre for Infectious Disease Modelling, MRC Centre for Global Infectious Disease Analysis, Abdul Latif Jameel Institute for Disease and Emergency Analytics, Imperial College London. https://www.imperial.ac.uk/media/imperial-college/medicine/sph/ide/gidafellowships/Imperial-College-COVID19-Global-Impact-26-03-2020.pdf

Wanqing, Z. (2020, March 2). Domestic Violence Cases Surge During COVID-19 Epidemic. Sixth Tone. https://www.sixthtone.com/news/1005253/domestic-violence-cases-surge-during-covid-19-epidemic

Wenham, C., Smith, J., \& Morgan, R. (2020). COVID-19: The gendered impacts of the outbreak. The Lancet, 395(10227), 846-848. https://doi.org/10.1016/S0140-6736(20)30526-2

Winter, S., Dzombo, M.N. \& Barchi, F. Exploring the complex relationship between women's sanitation practices and household diarrhea in the slums of Nairobi: a cross-sectional study. BMC Infect Dis 19, 242 (2019). https://doi.org/10.1186/s12879-019-3875-9

Wong, G., Liu, W., Liu, Y., Zhou, B., Bi, Y., \& Gao, G. F. (2015). MERS, SARS, and Ebola: The Role of SuperSpreaders in Infectious Disease. Cell Host \& Microbe, 18(4), 398-401.

https://doi.org/10.1016/i.chom.2015.09.013

World Health Organization. (n.d.). Coronavirus Disease Situation Reports. Retrieved March 25, 2020, from https://www.who.int/emergencies/diseases/novel-coronavirus-2019/situation-reports 